\title{
Research on designing and making of a mobile training facility for intervention and rescue personnel in toxic I flammable / explosive environments
}

\author{
George Artur Gaman ${ }^{* 1}$, Daniel Pupazan ${ }^{1}$, Cristian Nicolescu ${ }^{1}$, Cosmin Ilie $^{1}$ and Izabella \\ Kovacs $^{1}$
}

${ }^{1}$ National Institute for Research and Development in Mine Safety and Protection to Explosion INSEMEX Petrosani, 32-34 G-ral Vasile Milea Street, Postcode: 332047, Petrosani, Hunedoara County, Romania

\begin{abstract}
The decisive factor in ensuring success for an intervention and rescue operation in toxic or chemical aggressive environments lies in optimal and efficient design of the training process for rescue personnel, including intervention in confined spaces. The current paper shows the designing and making of a modern infrastructure - mobile training facility with different high difficulty degree training routes, allowing the simulation of intervention activities in confined areas, horizontally and vertically, spaces with low visibility, above normal limits temperature and humidity, etc. as well as the measurement of several physiological parameters (pulse, blood oxygen level, calories consumed, etc.) that allow permanent monitoring of rescuers' health condition during the training process. The mobile training facility consists of a space for physical training (endless ladder, impact device, treadmill, elliptical bike, stepper), an indoor training circuit and a control room that allows the coordination of all activities carried out within an exercise. The platform on which the training facility is placed can be moved to the business quarters where intervention and rescue activities take place, so that personnel engaged in this activity go through a complex training program, as close as possible to real-life interventions.
\end{abstract}

\section{Introduction}

When, as a result of damage, toxic gases are released or the composition of air is qualitatively changed, it is necessary to protect the airways of persons caught in these areas and of those entering the area to evacuate the injured and eliminate damage wearing protective breathing equipment [1].

\footnotetext{
* Corresponding author: artur.gaman@insemex.ro
} 
Intervention and rescue activities, in toxic / explosive / flammable environments, can be carried out exclusively by personnel trained and authorized in this respect, personnel who use individual respiratory protection equipment [2].

The decisive factor in ensuring the success of an intervention and rescue operation in toxic or chemically aggressive environments lies in the optimal and efficient design of a training process for rescue personnel, including for intervention in enclosures [3].

Training is a process of psychophysiological preparation, through which an increased (maximum) efficiency is attained in the professional activity of rescuers. Maximum efficiency is attained by raising the body's functional capacity to the highest degree. For this it is necessary to use systematic and methodical exercise [4].

Intensity of workout during training is conditioned by:

- individual possibilities of the rescuer;

- degree of preparedness;

- type of exercises;

- external conditions.

Their succession and gradation are rigorously planned, thus giving training a scientific character [5].

During training, the following psychophysiological objectives are pursued: learning motor skills, developing mental and physical motor activity qualities: speed, endurance, skill, will, perseverance, self-confidence, courage, determination, initiative.

Acquiring and developing motor skills is mediated by the central nervous system, which ensures the increase of body functions' efficiency and thus a high level of activity of the musculoskeletal system. It is a so called "internal organs training", that precedes the actual execution of physical exercises [6].

\section{Description of the mobile training facility}

INCD INSEMEX Petrosani has a stationary training facility, singular at national level, being similar to those used in countries with tradition in the field of rescue, which includes training spaces where practical training of rescuers takes place. Facilities, devices and operations performed during training are designed to be as close as possible to real conditions encountered in various types of emergencies.

At present, practical preparation in the process of training / retraining rescuers at economic agents' sites, is performed at their own facilities, under normal operating conditions, without being able to simulate difficult intervention conditions such as: low visibility, temperature and high humidity, enclosures, conditions that can be encountered in case of a real intervention [7].

In order to comply with safety and health at work regulations and for efficient operations, intervention and rescue personnel in toxic / explosive / flammable environments require good physical and mental training, achievable by using a modern training infrastructure (mobile facility) that can be made available to any economic agent regardless of place and nature of the activity carried out [8].

Documentation regarding putting together a mobile training facility had as a starting point the structure and equipment of the stationary training in closed spaces facility, endowment of the Risk Rescue Laboratory, within INCD INSEMEX Petrosani.

The mobile training facility (fig. 1.) is very complex, given the fact that it has fitness equipment, closed spaces with piping, niches, gas channel, etc., being designed to practice rescue in enclosures [9]. 


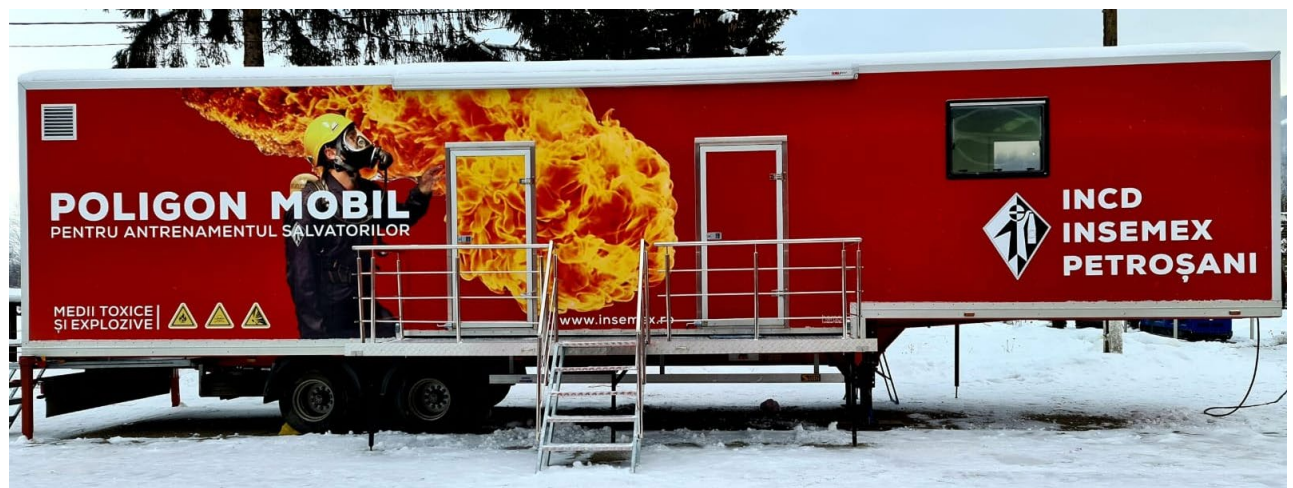

Fig. 1. Mobile training facility

The rescuers' mobile training facility is divided into 2 compartments, each with independent access from the external platform, as follows:

I. Compartment for fitness equipment and control equipment, comprising the following:

a. Infinity ladder with computer interface

b. Ergometer bicycle with computer interface

c. Treadmill

d. Impact device with computer interface

e. Stepper with computer interface

f. Control equipment

II. Enclosure compartment.

\subsection{Infinity ladder with computer interface}

Rescuers use an infinity ladder (fig.2.), that offers the possibility to electronically measure speed, for practicing climbing. The equipment has automatic safety systems, photoelectric sensors, a special braking circuit and electronic automatic start. A free wheel on the transmission shaft means that the endless chain can only be operated by the weight of the person exercising. The equipment automatically shuts off if the person exercising reaches the nominal value. Several people can practice consecutively, without the need to readjust the meter or climbing speed. The climbing speed can be adjusted between 3 and 25 meters / minute depending on the number of meters to climb.
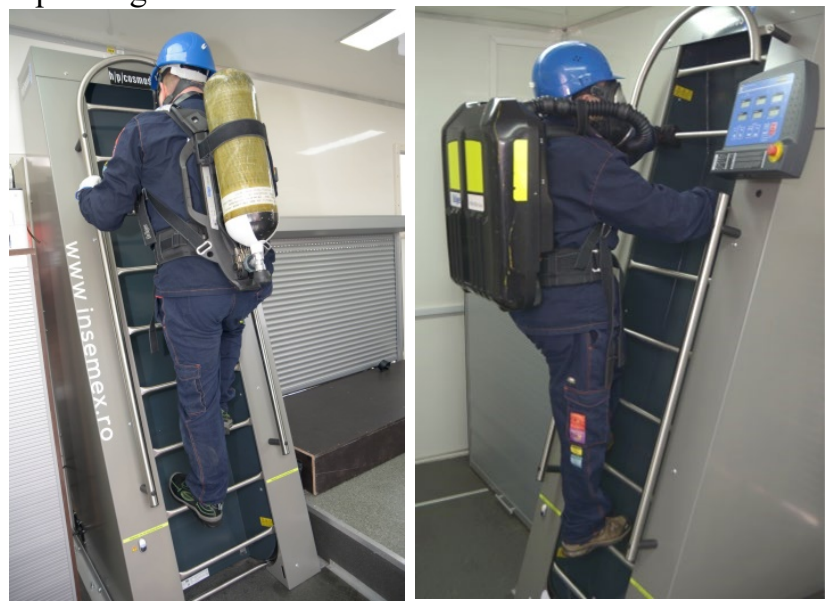

Fig. 2. Infinity ladder 
The infinity ladder's software is divided into 4 operating modes: Manual, Profile, Cardio and Test. 7 different levels of acceleration and deceleration are available for all 4 modes of use.

The digital display terminal displays the following information: climbing speed, training time, distance travelled, degree of elevation, energy consumed, heart rate.

\subsection{Ergometer bicycle with computer interface}

The training programs operate according to the principle of resistance independent of speed so that the pedalling frequency can be chosen arbitrarily, without thereby influencing the power. The device has two manual and two programmable training programs, as well as an automatic program with power regulation by impulse. Impulse power adjustment is guided by pre-set pulses for the training time.

The support frame has a welded, robust construction, which incorporates a silent pedal drive system, consisting of a chain and belting (fig.3.).

The "Time" training mode allows the user to perform an exercise with a low pre-set time. The "Distance" training mode allows the user to perform an exercise with a decreasing pre-set distance. The "Calories" training mode allows the user to perform a preset calorie burning exercise.

The digital display terminal displays the following information: pulse, power, rotational speed, training time and energy consumed.

Fig. 3. Ergometer bicycle

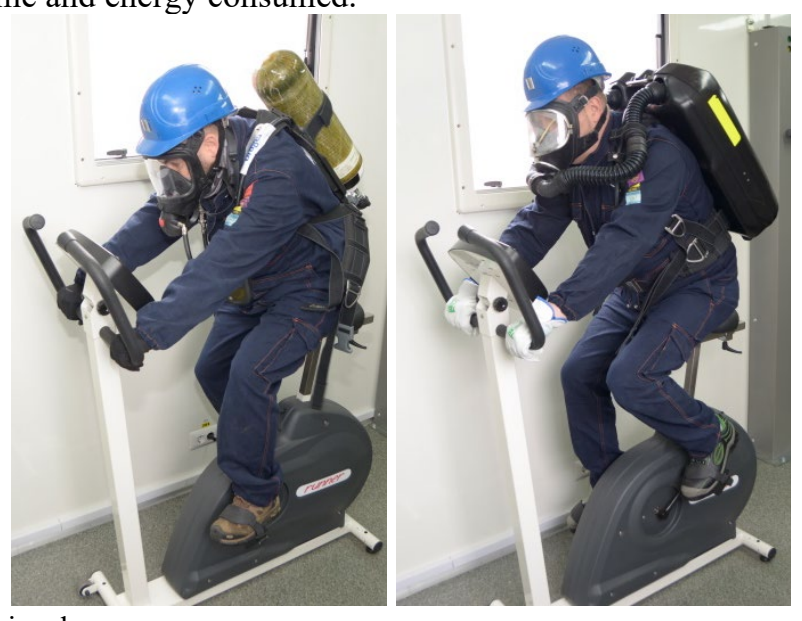

\subsection{Treadmill}

It is a device for testing the state of strain (fig. 4.), with an adjustable travel speed between 0.1 and $25 \mathrm{~km} / \mathrm{h}$ and with a variable inclination between 0 and $30 \%$. Oxygen consumption per body $\mathrm{Kg}$, depends, in this case, on speed and angle of inclination. The device is used efficiently for training the blood circuit, testing lungs functioning, strain tests as well as for testing the orthopaedic function.

Before starting any exercise, on the 10" colour programmable touch screen monitor, personal data can be configured (sex, age and weight). These values will be needed to correctly calculate the calories that should not be exceeded during exercise / testing. 
Fig. 4. Treadmill
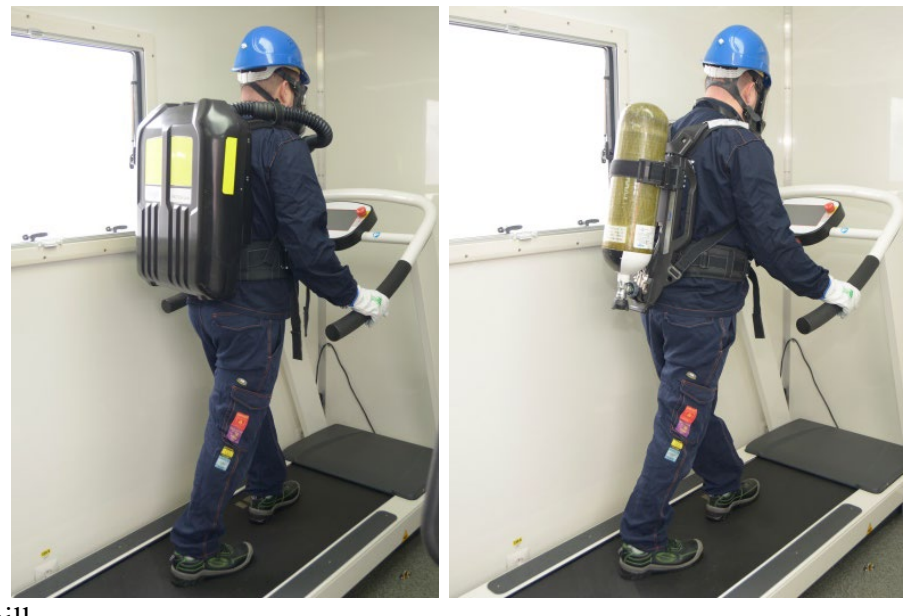

\subsection{Impact device with computer interface}

A $22 \mathrm{~kg}$ weight on the bearings, sliding on a steel frame (fig.5.). The weight drop is attenuated by a system fitted at the lower end point. The 1-meter-long cable is directed over a roller.

The ergometer serves to train rescuers, the workload performed allowing a correct analysis of the physical capacity of the person training. The weight is scanned by magnetic switches at the top and bottom. This ensures that the count includes only those tests in which the weight reaches the stop.
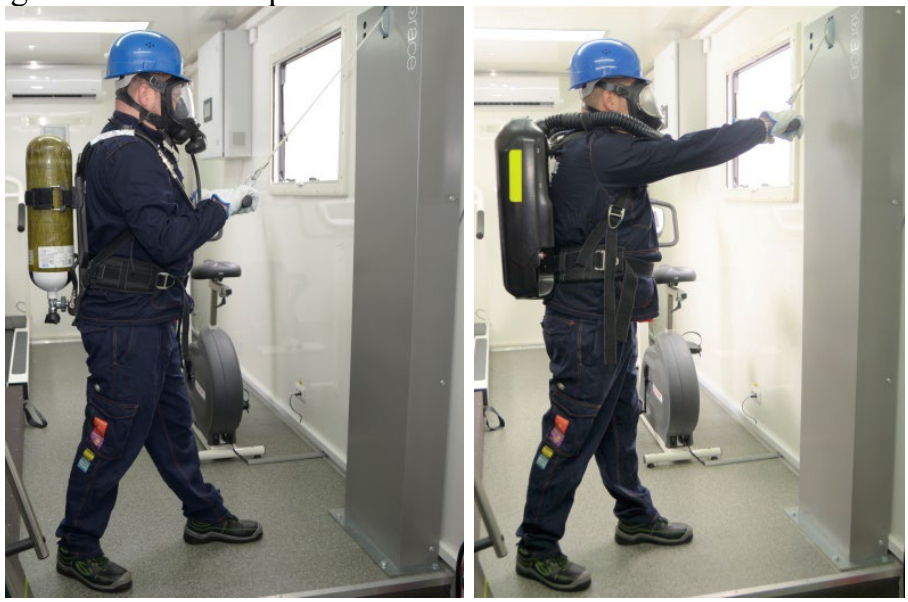

Fig. 5. Impact device

\subsection{Computer interface stepper}

The fitness equipment has several levels of performance, selectable between 0 and 600 watts and adjustable in steps of 1 watt. A speed range between 0 and $130 \mathrm{rpm}$ can be set. The pulse is measured through contact paddles fitted at palm rest's level and through a wireless strap that is positioned on the rescuer's body (fig.6.). 
The equipment's colour monitor is programmable, it has a 10" touch screen that allows the selection of several programs for monitoring the physiological parameters of persons training.

Fig. 6. Stepper
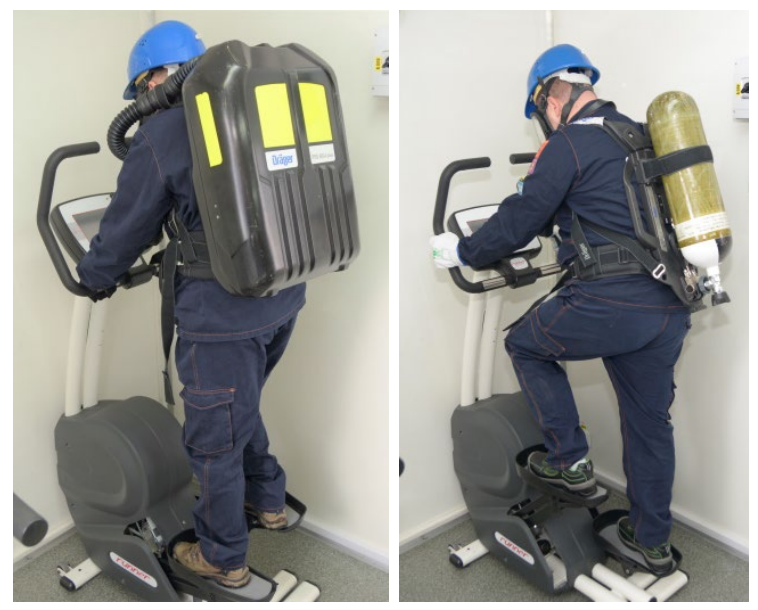

\subsection{Control equipment}

Rescuer's control equipment within the mobile training facility consists of: a control desk, a training control system and a telemetry system.

\subsubsection{Control desk}

It has integrated control and monitoring components for performance evaluation and recording of all elements and exercise data, performed during training (fig.7.).

The following are displayed on the four 22-inch monitors in the control panel:

- System status display (normal operation, emergency operation)

- System reporting history display and storage

- User management

- Display of the control voltage

- Lighting control

- Video camera control

- Ventilation control

- Monitoring the sensors in the floor of the training facility

- Control of orientation lights

- Route monitoring

- Door monitoring

- UPS operation indicator

- Fog machine control

- Noise effects of the control system

- Lighting effects of the control system

- Heat zone of the control system

- Hot areas control 


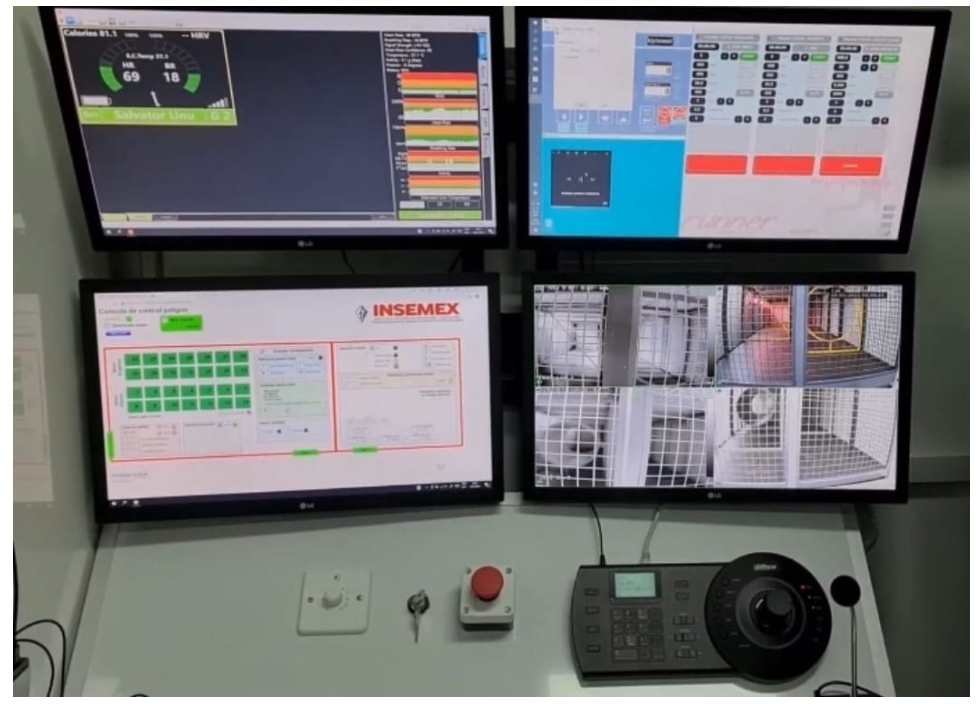

Fig. 7. Control desk

\subsubsection{Training control system}

It is used for monitoring and control of the entire training facility. Safety of users is ensured by an emergency circuit, which can be activated by an emergency stop button.

The control of fitness equipment through the control desk ensures a comfortable and safe monitoring of users and displays the following information:

- Infinity ladder: Operating time $[\mathrm{sec}]$, Speed $[\mathrm{m} / \mathrm{min}]$, Distance $[\mathrm{m}]$, Power consumption $[\mathrm{kJ}]$

- Bicycle ergometer: Operating time [sec], Degree of load [W], No. of rotations RPM $[1 / \mathrm{min}]$, Power consumption $[\mathrm{kJ}]$

- Treadmill: Operating time [sec], Speed [km/h], Degree of inclination [\%], Distance travelled [m], Power consumption [kJ] $[\mathrm{kJ}]$

- Impact device: Operating time [sec], no. of complete movements, Energy consumption

- Stepper: Operating time [sec], Degree of load [W], Distance travelled [m], No. of rotations RPM [1/min], Power consumption $[\mathrm{kJ}]$

\subsubsection{Telemetry system}

The Cardio control system is used for monitoring and optimizing workout. Regardless of the obstacle, the training system, even if performed in the enclosed space or in the fitness compartment, heart rate is constantly monitored online.

Before training, the limit values (minimum and maximum heart rate) will be set and a visual alarm will be triggered if these values are exceeded. The telemetry system has a protection against overload of the cardiovascular system.

The telemetry system includes:

- 6 CCS transmitters

- Charging station for 6 transmitters, including power supply unit

- Programming device including power supply unit

- 6 chest straps 


\subsection{Enclosure track}

The training area is made of a metallic structure, on several levels in the form of interconnected cells, so that training tracks with varying degrees of difficulty can be created (fig.8.).

The track within the mobile training facility is provided with floor pressure sensors, to monitor the presence of rescuers.

The track consists of areas for horizontal, vertical and inclined circulation, with a length of $800 \mathrm{~mm}$, a width of $900 \mathrm{~mm}$ and a height of $1000 \mathrm{~mm}$. It comprises 28 individual cells interconnected with each other, superimposed on 2 levels, the lower level - level zero, comprises 14 cells and the upper level - level one comprises 14 cells, resulting in a training track length of 22 meters.

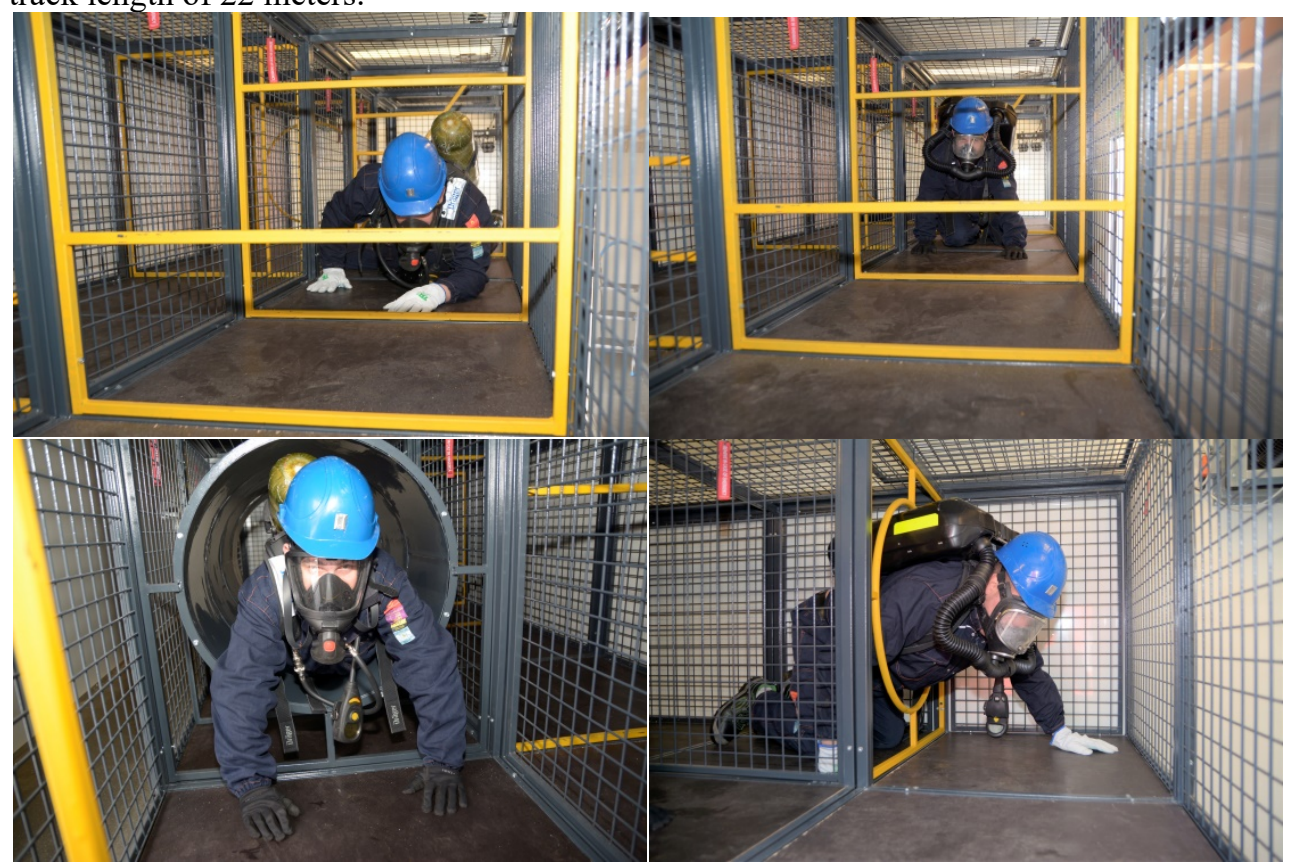

Fig. 8. Enclosure track

The following types of blockers are positioned on the track: circular hatch, square hatch, oblique blocker, upper horizontal blocker, bottom horizontal blocker, right vertical blocker, left vertical blocker, circular tunnel with minimum diameter of $600 \mathrm{~mm}$ and minimum length $1200 \mathrm{~mm}$, circular blocker. These types of blockers are interchangeable, so that several training routes, with different degrees of difficulty, can be configured.

Each cell in the training facility has a removable grid panel on the outside, that can be quickly removed by pulling a fuse, in case a rescuer has problems during the training exercise.

The location of the enclosure track within the compartment allows users to be evacuated through a safety corridor.

Low visibility environments can be simulated in enclosure track compartment, by using a machine that produces harmless artificial fog by vaporizing a non-oily liquid. The entire room is flooded with smoke within 1 minute.

A ventilation system shall be used to evacuate the smoke made by the artificial fog machine. This ventilation system maintains an air flow of up to $50 \mathrm{~m}^{3}$ volume, as well as 30 air cycles per hour, and removes all smoke from the room within 1 minute. 
For the training of rescuers in situations as close as possible to real ones, high temperature environments can be simulated within the enclosure compartment. The heat is generated by an electrical panel with a power of $4 \mathrm{~kW}$ used for simulating a fire source, only in a small area of the enclosure compartment, where the air temperature reaches up to $50^{\circ} \mathrm{C}$.

To amplify the feeling of realism, a set of projectors with 3 different lamps of $100 \mathrm{~W}$ is used, as well as an audio system.

In the enclosure compartment. the mobile training facility is equipped with two thermal imaging cameras and 2 infrared cameras, which allow instructors to supervise students during training, even if the space is flooded with fog, both during the day and in the dark.

In the enclosure compartment, rescuers perform 2 training circuits. In the first circuit, the rescuer travels the track, for exploration. At this time, none of the existing resources are activated so that the rescuer can identify particularities of the route. In the second circuit, the rescuer travels the track in difficult conditions of heat, noise, strong lights and smoke. The operator in the fitness area activates the floor sensors (in order to be able to identify, in real time, the position of rescuers on track), turns off the general lighting, starts the fog machine, turns on the lighting system, turns on the audio tape on the control panel.

The mobile rescue training facility consists of a complex intervention and rescue system with remote personnel monitoring, consisting of 8 respiratory protection devices and a control system (fig. 9.).

The complex intervention and rescue system is based on the Ariac Diablo device, produced by PROSALV BUZAU and is an insulated, autonomous, open circuit, compressed air respiration protection equipment, intended for medium-term interventions, ensuring an operating range of approximately 45 minutes.

The monitoring and warning device and the control system form a support system for respiration monitoring and protection. This system is part of the respiratory protection device and uses the principle of data transmission through radio waves.

The Monitoring and Warning device is part of the respiratory protection device and has the purpose of monitoring air level in the cylinder, lack of movement and ambient temperature. It also serves to warn the user upon low levels of air in the cylinder and to initiate an alarm when the user does not move for a period of time.

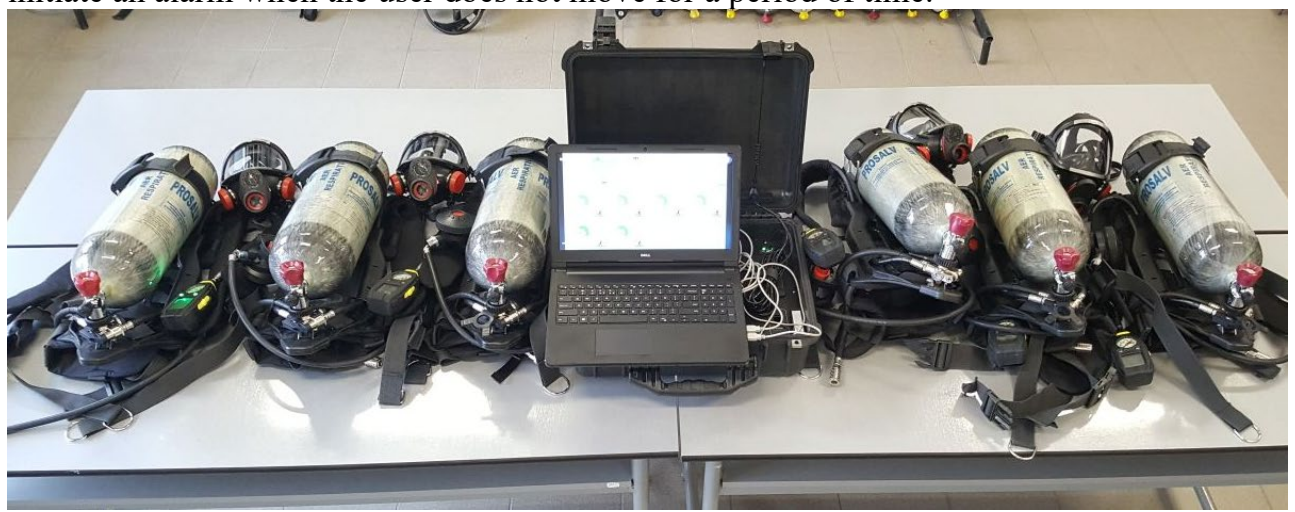

Fig. 9. Complex system of intervention and rescue

At the end of training, the operator of the mobile facility marks the completion of the enclosure track and of the fitness training, completes his personal data, confirms the correctness of data and saves the information. At this point, the test sheet receives a unique code in the database and is stored in the facility's archive. It is possible to save this file in .pdf format, for printing, physical archiving or for handing it to the rescuer, as proof of his participation in the test. 


\section{Conclusions}

Training of rescuers in the mobile training facility leads to increased levels of safety and health at work, by increasing the safe intervention capacity, in case of damages, accidents, disasters, etc.

Development of a mobile training facility will lead to development of the practical training infrastructure for intervention and rescue personnel in toxic/ explosive/ flammable environments, allowing for research studies with the final objective of elaborating and implementing selection and training procedures for intervention and rescue teams working in confined spaces, both within INCD INSEMEX as well as at economic agent's rescue stations.

Various training scenarios with various degrees of difficulty can be created within the mobile facility, allowing simulation of intervention activities in confined, horizontal and vertical spaces, with low visibility, high temperature and humidity environments, etc., aiming at training intervention and rescue teams for situations close to real ones.

The mobile training facility represents an easier approach to the process of training intervention and rescue personnel, which can now take place at the headquarters of beneficiaries, who thus no longer have to make their staff unavailable during training, with all the associated benefits (logistics, financial, etc.). It also offers the possibility of constant monitoring of rescuer's physiological parameters (heart rhythm, blood pressure, blood oxygen, etc.) during training, with the help of equipment provided by the mobile training facility.

Benefits for economic agents, beneficiaries of the training - authorization activity of intervention and rescue personnel in toxic / explosive / flammable environments which, by using the mobile facility, will ensure an increase in health and safety at work, accident prevention capabilities, and more effective protection of patrimony susceptible of being destroyed or disabled by accidents or break-downs.

\section{References}

1. G.A. Gaman, Rescue in toxic environments, Insemex Publishing (1997)

2. G.A. Gaman, Techniques and methods for operative interventions and rescue of persons in toxic and explosive environments, Insemex Publishing (2003)

3. G.A. Gaman, C. Lupu, D. Pupazan, Procedures and regulations of the intervention and rescue teams in toxic / inflammable / explosive environments, Insemex Publishing (2009)

4. D. Pupazan, G.A. Gaman, C. Ilie, A. Calamar, The intervention of rescue teams in toxic / inflammable / explosive environments, Focus Publishing (2017)

5. G. Babut, R.I. Moraru, C. Dura, Conceptual and methodological Framework for Risk Analysis and Evaluation on Seveso Industrial Sites (I) Risk Evaluation Terminology, Objectives and Stages, Quality - Access to Success Journal, 16 (145), (2015)

6. C. Ilie, G.A. Gaman, D. Pupazan, A. Irimia, A. Gireada, Evaluation systems for intervention and rescue personnel in toxic / explosive / flammable environments in the extractive industry, Focus Publishing (2016)

7. PN-19 2102 03, Developing the practical training infrastructure for intervention and rescue personnel in toxic / explosive / flammable environments by building a mobile training facility (2019 - 2021)

8. C. Nicolescu, I. Kovacs, C. Ilie, Training of intervention and rescue personnel in toxic / explosive / flammable environments INSEMEX Publishing (2018)

9. A. Gireada, D. Pupazan, C. Nicolescu, C. Ilie, A. Irimia, Optimizing the training process of intervention and rescue personnel in toxic / explosive / flammable environments, INSEMEX Publishing (2019) 